International Journal of Linguistics, Literature and Translation

ISSN: 2617-0299 (Online); ISSN: 2708-0099 (Print)

DOI: 10.32996/ijltt

Journal Homepage: www.al-kindipublisher.com/index.php/ijllt

\title{
Exploration of the Compilation of English Learning Materials for Chinese College Students Based on Big Data under the Guidance of Complex Dynamic Theory
}

\author{
Mao Feng 1 8(D), Li Quan 2 8(D), Wu Biyu ${ }^{3}$ 8(D) \\ ${ }^{1}$ Associate professor of School of Languages, Shanghai University of International Business and Economics, China \\ 2 Master, Shanghai University of International Business and Economics, China \\ ${ }^{3}$ Professor of School of Foreign Languages, East China University of Science and Technology, Shanghai, China
}

$\square$ Corresponding Author: Wu Biyu, E-mail: maofeng@suibe.edu.cn

\author{
ARTICLE INFORMATION \\ Received: February 01, 2021 \\ Accepted: March 07, 2021 \\ Volume: 4 \\ Issue: 3 \\ DOI: 10.32996/ijllt.2021.4.3.3
}

\section{KEYWORDS}

Complex Dynamic System Theory,

Compilation of College English

textbooks, Big data, Visualized

analysis

\section{ABSTRACT}

With the help of big data and Citespace software, this research makes a statistical analysis of the journals and dissertations on College English teaching and learning materials collected by CNKI from 2011 to 2020. This paper, based on the knowledge map drawn by the visualized analysis of literatures volume, authors, research institutions and keywords clustering, analyzes the current research status and hotspots in the compilation of China's College English textbooks. It is found that there are six problems in the compilation. Because of the complexity of teaching and learning materials and the dynamic progress of language learning, the nature of English teaching and learning materials is bound to turn from a learning tool to learning resources. Thus, this research, from the perspective of Complex Dynamic System Theory, attempts to develop big data-based College English learning materials with digital, individual and multi-dimensional characteristics by three paths: the establishment of big data-based English learning behaviors index system, the development of big data-based College English learning materials and the application of big data-based College English learning materials. This paper will explore a new way of developing China's College English learning materials, improve and optimize the compilation and development of College English learning materials in China.

\section{Introduction}

College English is a public basic course stipulated by the Ministry of Education in China, which plays an important role in the curriculum system of China's colleges and universities. Since the mid-1980s, the Ministry of Education has guided, supervised and promoted College English teaching through nationally planned teaching materials, Teaching Syllabus, Teaching Requirements for College English Course, and the National College English Test Band 4 and 6. Under the great concern of the Ministry of Education, College English has quickly become the largest, the most popular and the most influential course for undergraduates in China's college curriculum. However, the huge investment of the Ministry of Education has not paid off as time consuming and inefficiency are still the major problems in China's College English education.

As an important basis for teaching, textbooks have direct impacts on teaching quality and learning effect; thus, they are the most important factors in education (Yan Lin et al., 2019). Adopting literature measurement analysis, this research takes "compilation of College English textbooks" or "development of College English textbooks" or "compilation of public English textbook" as subject terms to search published literatures collected in CNKI from 2011 to 2020, and draws knowledge maps through a visualized analysis of literature volume, authors, research institutions and keywords clustering, in order to study and reflect on the compilation and status quo of College English textbooks in China.

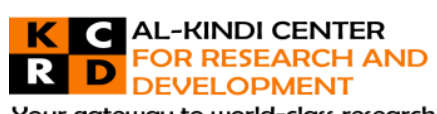

Your gateway to world-class research

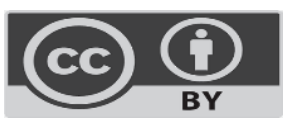

Published by Al-Kindi Center for Research and Development. Copyright (c) the author(s). This open access article is distributed under a Creative Commons Attribution (CC-BY) 4.0 license 


\section{Data source and research method}

This research adopts a visualized method to analyze the knowledge map of the literatures on China's College English textbooks compilation, which are obtained from CNKI database.

\subsection{Data source}

In this study, CNKI is used as the source of literatures search. In CNKI database, "compilation of College English textbooks", "development of College English textbooks" or "compilation of public English textbooks" are as subject terms to conduct a search, and the search date is from January 2011 to December 2020.The number of relevant literatures on this topic is 372 , including conference papers, books, newspapers, journals and dissertations.

\subsection{Research methods}

The mapping of scientific knowledge relies on the combination of database, Excel table and analysis software. In order to intuitively and concisely reflect relevant information about China's College English textbooks compilation, this paper uses Citespace, an analysis software developed by Professor Chen Meicao from Drexel University, conducts data mining on the research samples to generate the knowledge map of College English textbooks research in China. With further literature reading and study, the paper analyzes the development status and research hotspots of this field. The knowledge map drawn by Citespace is not only reader-friendly, but also scientific and rational. To some extent, this method overcomes the shortcomings of traditional literature review.

\section{Findings}

In order to grasp the current research status, research hotspots and developing trends of China's College English textbook compilation, this paper makes a systematic review of the literature characteristics, research entities, research hotspots and frontier research of this field.

The basic measurements of literature data include the time distribution of literature, source journals, publishing institutions, authors, keywords clustering view and other contents. Through the quantitative analysis and visualized research of literature data, it is helpful to have a more direct and comprehensive understanding of research information in this field.

\subsection{Literatures volume}

The chronological distribution of literatures can show the relationship of quantity and published time. The change of the number of literatures over time is helpful to explore the research progress of this theme and the reasons for the fluctuation of the quantity curve. This paper makes a statistical analysis of the quantity and published time of literatures about College English textbooks compilation, and the result is shown in Figure 1.

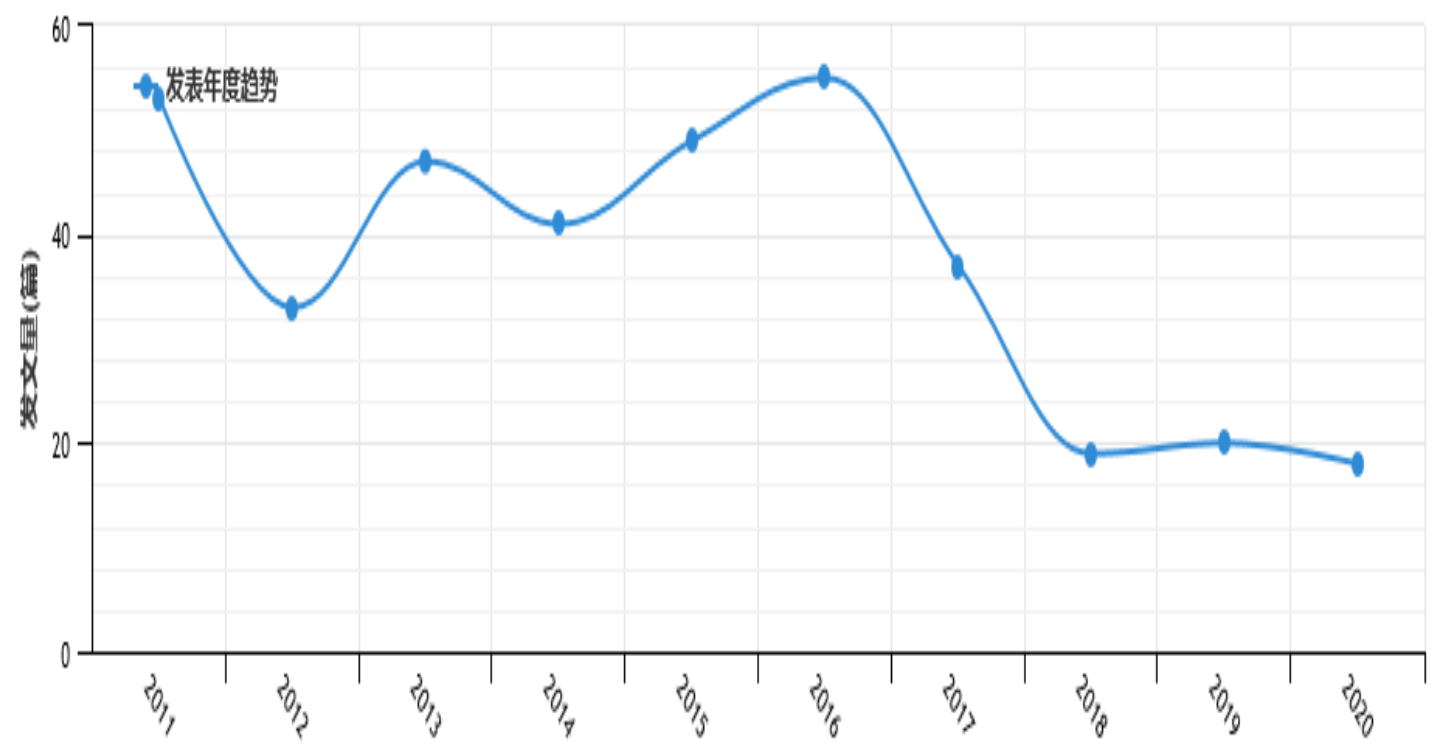

Figure 1. Annual distribution graph of College English textbooks compilation

It can be seen from Figure 1 that the research on the compilation of China's College English textbooks is mainly divided into two obvious stages. (1) Initial development period (2011-2016). In this stage, there were 278 papers on the compilation and 
development of College English teaching materials, accounting for $74.7 \%$ of the total published papers in the past ten years. In general, there are a large number of papers, and the annual publication volume is basically fixed at about 40 papers. The number of issues increased to 55 in 2016, the highest in the past decade. The period from 2011 to 2015 is the 12th Five-Year Plan period of China. Education development is one of the key projects. China has implemented the strategy of rejuvenating the country through science and education and the strategy of strengthening the country through human resources development, and accelerated the building of an innovation-oriented country. The Ministry of Education in China has also issued opinions on the setting up of colleges and universities during the 12th Five-Year Plan period. With the gradual advancement of College English teaching reform, scholars have begun to pay more attention to the construction of College English teaching materials, which promotes the development of College English teaching materials to enter an unprecedentedly prosperous development period. (2) Stable development period (2017-2020). At this stage, the curve is not obvious. After 2017, the total number of articles published per year is about 20, which is generally small and has a steady growth. These data show that under the background of education internationalization, scholars have paid some attention to this field, but the research on College English textbook compilation is still in the growth stage.

\subsection{Published journals}

The types and the number of published journals, to some extent, reflect the research direction and the development trend of this field. In the research process, core journals play important roles in promoting the development of this field, and provide good communication platforms for the development of this research. Papers on the compilation of College English textbooks have been published by 20 Chinese core journals. Figure 2 provides the periodical distribution of its literatures.

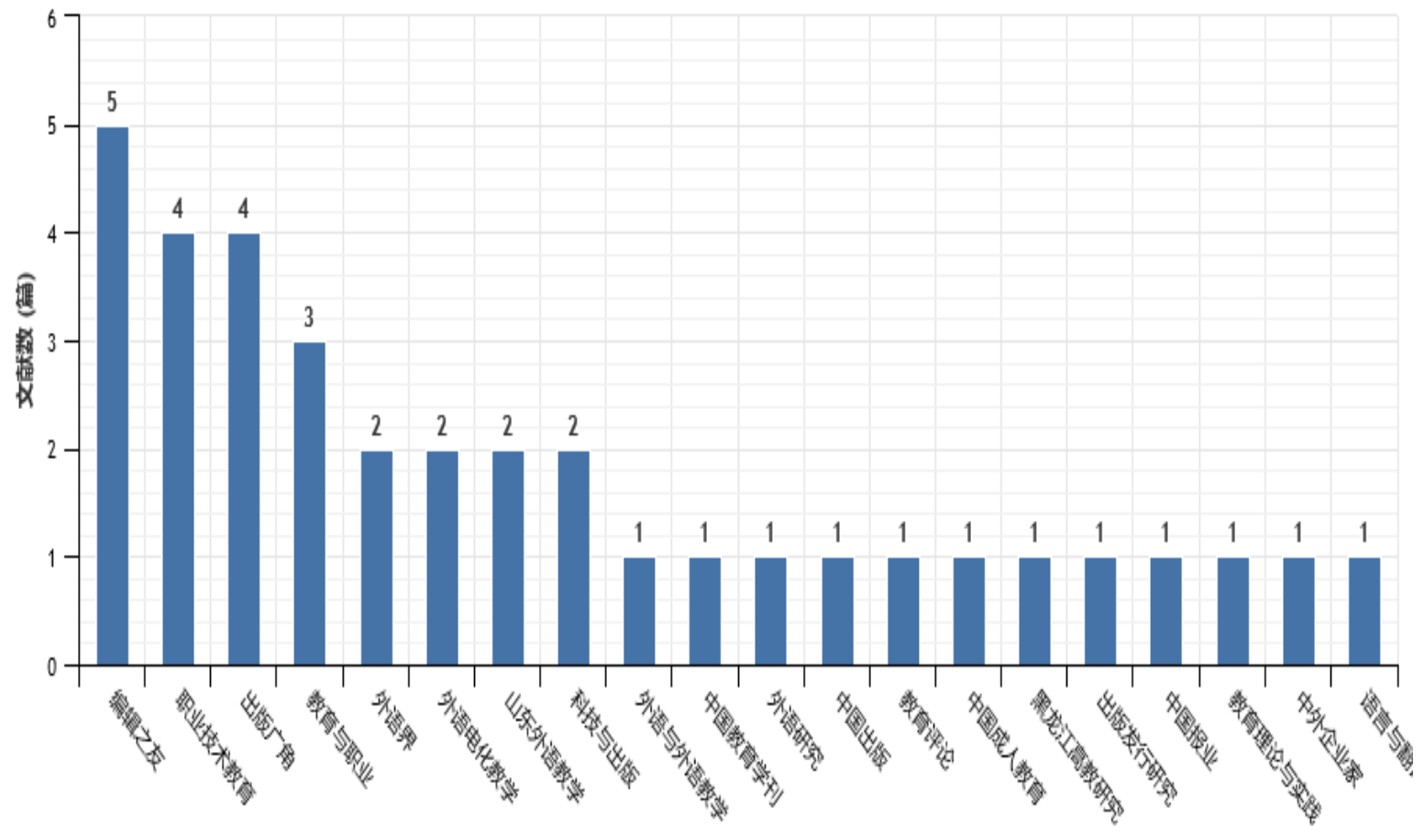

Figure 2. Distribution of core journals in College English textbook compilation research

From Figure 2 we can see, 20 journals are involved in publish literatures about College English textbooks development. Among them three are influential core journals in China, namely Editorial Friend, View on Publishing, Foreign Language World, and Computer-assisted Foreign Language Education. Most of the papers published by Editorial Friend focus on the characteristics of College English textbooks in compilation, the demand of learning materials compilation for independent colleges and some non-English majors. Foreign Language World mainly discusses the main problems and suggestions in developing College English textbooks, as well as how to apply the teaching method to the compilation of a specific textbook. Computer-assisted Foreign Language Education reviews the development of College English textbooks in the past twenty years and proposes the compilation and content of English teaching and learning materials should be based on majors. However, in general, the quantity and quality of papers written about the development of College English textbooks are relatively insufficient, with only about $10 \%$ of them published in core journals. 


\subsection{Authors}

The core authors among those that have published papers are the core strength of the research. The number of publications and their references has gradually become important factors to measure an author' contributions to scientific research, and can reflect his academic research ability as well as the development status of the field to some extent.

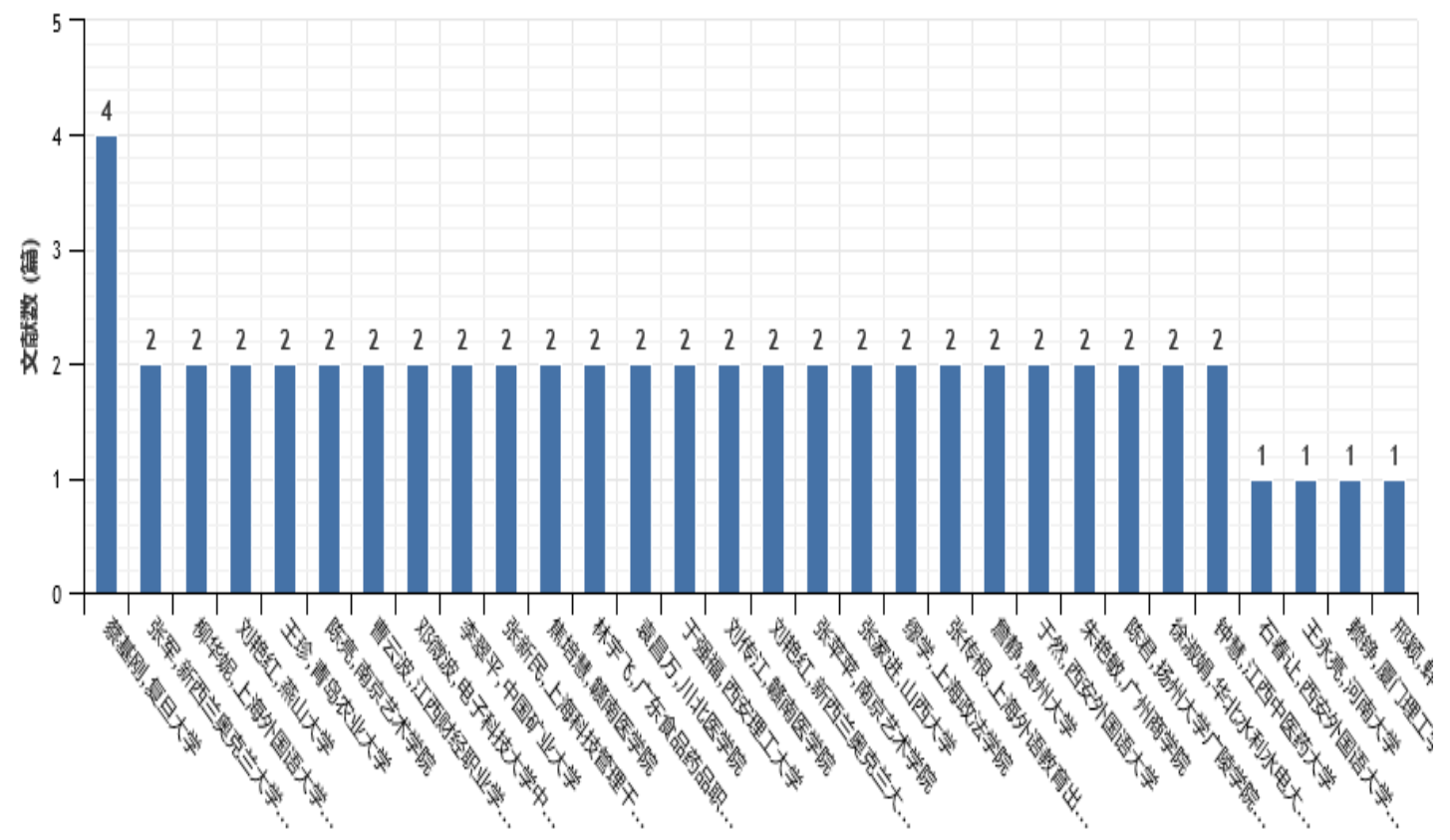

Figure 3. Authors' distribution

Figure 3 shows that from the CNKI database, and we can see about 20 top authors are in the field of studying College English textbooks compilation in the past ten years, among whom Professor Cai Jigang from Fudan University has published 4 relevant papers on English teaching and learning compilation. According to statistics, Professor Cai has published 179 articles with a citation rate as high as 367,257 . Besides, most of his papers have been published in the core journals, such as Foreign Language World, Foreign Language Education, Foreign Language Teaching and Research, Foreign Language Learning Theory and Practice, which indicates that this field of research has attracted the attention of influential scholars in foreign language field.

Cai Jigang (2011) believed that College English textbooks must keep pace with the times amid changes of the society and the global environment to make a breakthrough in the compilation. Zhang Xuemei (2019) proposed that the primary task of College English teaching and learning materials compilation in the new era was to clarify what talents should be trained by College English teaching. The development of College English teaching and learning materials should also meet the demands of the times to ensure the correct direction and quality of English teaching. However, there are few high-level researches focusing on the compilation and development of College English teaching and learning materials, and few research conclusions are embraced with a high degree of consensus and have strong persuasion.

\subsection{Keywords}

Keywords are highly generalized and condensed expressions of a paper, presented in short and concise words or phrases. By analyzing the frequency and centrality of keywords, we can have a more in-depth and comprehensive understanding of relevant topics in the compilation of College English textbooks in China.

In this research, Citespace is used to investigate the topic of China's College English textbooks compilation. First, import relevant data, and then set relevant parameters. Time slicing is set as 2011-2020. Year per slice is set as 1, and the Term source selects Title, Abstract, Author Keywords and Keywords Plus. In Node Types, check Keywords. Finally, click Go to run the visualization software. It can be seen from the map parameters that the number of nodes is 296 , the number of connections between nodes is 535, and the density is 0.0123 . A total of 11 clusters are generated. The results are shown in Figure 4. 


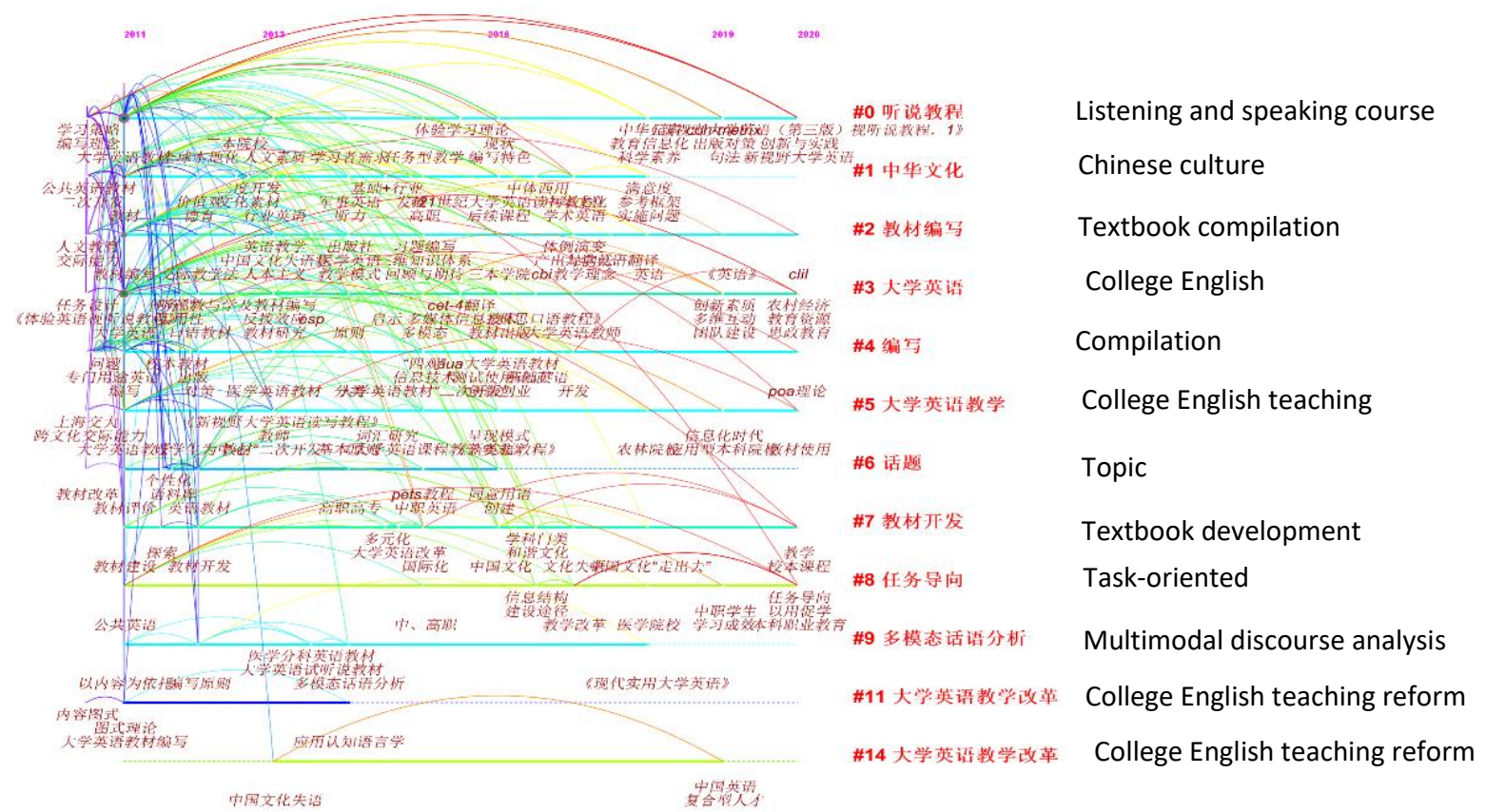

Figure 4. Keywords time line map of the compilation of College English textbooks in China

Keywords in figure 4 reflect the themes of the research on the compilation of China's College English textbooks in recent ten years, and reveal the research hotspots and development trends in this field. The smaller the label of the cluster is, the higher the research heat of the cluster is. The figure has a total of 12 cluster tags, listening and speaking tutorial as the core with multidirection and multi-level. Keywords clustering include Listening and Speaking course, Chinese culture, College English textbook compilation, topics in College English teaching, textbook research and development, task-oriented, multimodal analysis in College English education. In addition, the figure shows the developing status of the research topic in the time frame. The more articles published a certain time line has, the more published results are in this period and vice versa. As shown in Figure 4, the links between 2011 and 2016 are relatively intensive, indicating that the research results of this topic during this period are abundant in both perspectives and numbers. The thematic studies on clustering 0 and clustering 2 to 5 have been carried out up to now, meaning that there are many literatures in these fields and they still attract the attention of some scholars. But on the whole, there are more subjective and micro researches than macro and empirical researches.

Accordingly, this paper, based on the analysis of previous scholars' research, in combination with keywords time line map, tries to summarize and generalize the research hotspots of the compilation of China's College English textbooks. This topic can be macroscopically divided into five research hotspots: research of listening and speaking textbooks, research of the application of textbooks, research of textbook themes, and research of the development of multimodal College English learning materials.

\section{1) Research on listening and speaking College English textbooks}

When studying the compilation of College English textbooks, many scholars take audio-visual textbooks as an example. From the perspective of cross-cultural communication, Lin Sicheng and Xiao Lizhang (2015) research the second development of audiovisual textbooks. First of all, they analyze the advantages and limitations of the textbooks, and claim the textbooks give too much focus on listening skills, while ignoring the speaking ability and output process, yet listening and speaking skills should be matching. Su Wei (2016) makes an objective assessment of English Audio-Visual and Speaking Course (Language Skills) through questionnaire and data analysis. He thinks that the advantage of textbooks lies in its emphasis on the cultivating language foundation and communicative competence. But the communication is not natural in real conversation, lacking authenticity, and it's difficult to improve oral competence.

With the development of College English teaching reform, the compilation of Audio-Visual and Speaking Course has also undergone some reforms. Xu Jinfeng et al. (2020) believe that the Audio-Visual Course embodies the characteristics of audiovisual practice, attaching importance to the combination of tradition and innovation, stressing the creation of real context, and emphasizing "learning by doing". Wei Wenzheng (2020) considers that the content of the book has distinct characteristics, the material selection is full of the spirit of the times, and the writing logic is rigorous. 
In general, the compilation of College English textbooks pays less attention to listening and speaking but more attention to reading. As a result, the single ability cultivated by the textbooks conflicts with the comprehensive development that students need.

\section{2) Research on the application of College English textbooks}

At present, there are obvious deficiencies in the compilation of College English textbooks, and many of them fail to achieve the goal of teaching reform in actual use (Chen Jianlin, 2007), which shows obvious test-taking tendency (Cai, 2011; Guo Yan \& Xu, 2013). Wang Chuming (2014) believes test-oriented exercises are boring, unable to "stimulate students' endogenous expression power"

Zhou Xiaohui (2013), starting from the four factors of teachers, students, textbooks and courses, summarizes many reasons for the "secondary development" of textbooks, and believes that the textbooks can be creatively developed from macro and micro levels by means of deletion, supplement, replacement, sequence adjustment, task adaptation and expansion.

Guo and Xu (2013) conduct a questionnaire survey on the use of College English textbooks for Non-English major college students in China, and find that students' learning of College English textbooks is still exam-oriented, and their self-directed learning awareness and ability are relatively weak. The students' overall satisfaction with the College English textbooks is fair, but their interest in the contents of the textbooks is low. The textbook neglects the cultivation of language ability of professional and general academic purposes.

English teaching is to help students with the academic ability in professional learning, but not the comprehensive ability in English examination; Textbooks do not help students learn by themselves, but help them develop the ability of autonomous learning (Cai, 2011). However, the current compilation of textbooks pays more attention to examination-oriented education and ignores the needs of quality-oriented education and students' individualized development.

\section{3) Research on College English textbook themes}

As for the research on the theme of textbooks, scholars pay more attention to the embodiment and communication effect of Chinese culture in English textbooks. Luo Dan (2013) and Zhang Le (2013) explore the flaws of the culture in English textbooks, such as the lack of cultural material, monotonous task design, etc. They put forward the corresponding cultural material "secondary development" advice, thinking that the teacher may supplement missing culture data, excavate cultural connotation of the material, and develop cultural consciousness for the purpose of meeting the requirements of the own culture teaching.

Lu Hongbo and Tao Wenhao (2018) point out that the current College English textbooks generally pay attention to British and American culture, while Chinese culture is seriously missing. Based on the analysis of what causes his phenomenon, their paper proposes that College English textbooks should break the tradition, keep pace with times and integrate into Chinese cultural elements. It is necessary to be careful about the selection of materials and the establishment of a team of professional teachers to ensure that the compiled College English learning materials contain Chinese cultural elements.

\section{4) Research on College English textbooks for specific purposes}

Generally speaking, the researches on the compilation of specialized English textbooks mainly focus on two aspects: one is about the compilation of English textbooks for art students, and the other is for medical students.

Nowadays, colleges and universities choose different College English textbooks for art students. However, most textbooks are too difficult for art students, and lack professional relevance and practicality (Yuan Jing \& Wang Limin, 2015). Likewise, medical English textbooks also have some shortcomings. We hope that the teaching syllabus guiding the development of specialized English textbooks will be published as soon as possible to solve the connection between general English and specialized English (Wang Changyou, 2015).

With the further implementation of the "teaching quality and teaching reform project in institutions of higher learning" put forward by the Ministry of Education, colleges and universities focus more on the training of applied talents. As the basic tool of teaching, textbooks are the carrier of knowledge. However, most of the existing College English textbooks in China aim at cultivating students' language ability, and many universities generally lack appropriate textbooks in the process of cultivating applied talents (Zhu Qian, 2020). The development of teaching and learning materials should coordinate the relationship between basic education and general education, general English and specialized purpose English, so as to improve the quality of interdisciplinary talents. 


\section{5) Development of multimodal College English learning materials}

In recent years, with the rapid development of science and technology, many universities in China have begun to explore the integration of traditional teaching with technology. The multimodal material covers the characteristics of the common unimodal material. At the same time, it also has some characteristics which are different from the common unimodal textbooks.

MOOC, as a new educational concept and teaching mode, has exerted a great impact on the traditional educational one. It not only drives the reform of College English teaching, but also puts forward higher requirements for College English teaching and learning materials. Xu Dandan (2016) analyzes the characteristics of College English teaching under the background of MOOC, and then proposes the design of developing online courses to improve digitalized English teaching and learning materials. Zhang Delu and Zhang Shujie (2010) discuss the compilation principles of paper textbooks, electronic textbooks and demonstration textbooks respectively.

Chen (2007) believes that the first three generations of College English textbooks were developed and compiled based on the concept of "teacher-centered", while the fourth generation of College English textbooks, although ostensibly based on "studentcentered", did not break the "teacher-centered" teaching mode in fact. Multimodal discourse analysis, under the guidance of the fifth generation of College English textbooks, aims at "teachers as the leading factor, students as the main body, and learning as the center", through audio simulation, content cognition, culture acquisition, communicative practice and output language and repeated cycle for "independent learning, individualized learning, situational learning and cooperative learning".

\section{Discussion}

The above research results show that most scholars discuss about the textbooks that they have participated in compiling, including the introduction of the features of textbooks and compiling ideas, the revision instructions and so on. Most other researchers also evaluate textbooks via teachers' and students' questionnaires or according to their teaching experience. Many scholars talk to themselves and mutual recognition is not high. Few researches and papers on College English textbooks discuss the theme with unique visions and new technology background. Likewise, few scholars can explore the research and development path of college students' English learning ability effectively according to China's national conditions and the needs of the new era. The following problems still exist in the compilation of College English textbooks:

1) The conflict between globalized consciousness and national identity. There is a serious imbalance between Chinese culture and the western culture in the textbooks. The implicit ideology and cultural orientation in the textbooks are problematic. The textbooks generally guide students to accept the western ideas, values and lifestyles of consumption culture, and fail to express the traditional knowledge of Chinese local culture.

2) The conflict between basic education and general education. The compilation of textbooks still focuses on the basic English education and lacks general education. With the deepening of the popularization of English education in China, students have completed the basic English education before they go to college, and it is no longer appropriate for them to continue to learn basic English after they go to college.

3) The conflict between traditional forms and application of science and technology. The main carrier of textbooks is paper books, which have a single form. They cannot be updated at any time, but also cause a waste of resources due to the low utilization rate of textbooks.

4) The conflict between exam-oriented education and quality-oriented education. Under the influence of CET-4 and CET-6, the textbooks are compiled as exam-oriented education services, which lack comprehensiveness and cause students to learn English passively.

5) The conflict between wholeness and individuality. College English textbooks are often written for the whole students, and college students cannot make an individualized choice.

6) The conflict between single capacity and comprehensive development. The compilation of College English textbooks is still dominated by English reading textbooks, which is relatively simple and lacks comprehensive listening and speaking materials. Listening and speaking materials are also mainly daily dialogues, with few coherent listening and speaking exercises.

Based on the above conflicts, we might as well change the train of thought. Perhaps traditional textbooks have been unable to meet the needs of various types and levels of learning. What modern college students need is not some effective learning methods suitable for everyone, but a set of basic principles to help them build a classroom environment suitable for local actual needs. Professor Marjolijn Verspoor (2017:159) of the University of Groningen in the Netherlands points out that "The task of a teacher is not teaching itself, but to create a favorable environment in which the individual's best learning path can be realized". 
Therefore, based on the Complex Dynamic System Theory, this research takes big data as the new perspective to develop China's College English teaching and learning materials, and explores a way of the research and develops College English textbooks with big data that meets the needs of modern college students.

\section{Prospects}

Education is the most complex problem in the world, so it needs to be understood in a complex way of thinking in order to achieve a breakthrough. The thought of Complex System breaks through the traditional simplified and linear thinking paradigm, focusing on the connection and integrity of things. The Complex Dynamic System Theory regards language as a complex, dynamic and systematic whole with self-organization, adaptability and openness (De Bot et al. 2007). Language teaching from the perspective of Complex Dynamic Systems does not advocate a single teaching method, nor only focuses on the progress of a single direction, but emphasizes more on the dynamic, complex and overall construction of language competence. (Zheng Yongyan, 2019) The scientific content arrangement is closely related to the teaching quality and students' language ability.

First of all, the content of the teaching and learning materials is complex. Textbook compilers or editors need to consider not only teachers, but also students, as well as national policies, cultural literacy and social needs. Secondly, the content of the teaching and learning materials is dynamic. The users of textbooks (each student or individual teacher) will have different demands for learning content under the influence of teaching resources, modern teaching equipment, cultural environment, social environment and other factors. In addition, the learning process is a dynamic process. Each student has different learning progress due to different learning styles, motivations, interests or strategies. Therefore, traditional textbooks can neither provide support for the developing digital, personalized and multi-dimensional teaching, nor meet the needs of multi-types and multilevel learning. In the era of big data, corpus data is characterized by complexity, dynamicity, authenticity, universality, historicity, interdiscipline, omnimedia and barrier-free (Zheng Tongtao \& Zeng Xiaoyan, 2016), which can provide new ideas for the research and development of College English textbookls. Therefore, in order to improve and optimize the compilation and development of China's College English textbooks, a practical implementation path can be formulated based on the development principles in combination with the characteristics of the era of big data corpus.

\subsection{Development principles}

The development of big data-based College English teaching and learning materials is in line with the development of the new era, the progress of science and technology and the needs of the society, which has three characteristics: digitalized, Individualized and multi-dimensional.

\section{(1) Digitalized}

Information age provides humans with the broadest teaching resources, teaching materials of corpora data sources, which include written corpora, such as newspapers, magazines, news, novels, letters, diaries, brochures and others, and spoken corpora, such as broadcast, meetings, interviews, debate, preaching, talking face to face, telephone conversation, public discussion and so on. From the perspective of big data, teaching resources adopt more extensive and diverse information technologies, using data mining tools to transform data into knowledge, which provides broad support for foreign language teaching resources in China.

\section{(2) Individualized}

Teaching resources from the perspective of big data can provide personalized teaching resources for learners with different backgrounds. Big data mining tools are used to analyze learners' learning behaviors, and learners' expectations and applications are counted according to the data to develop teaching and learning materials suitable for their use. Based on the analysis of learning behavior, the needs of teaching and learning materials can be investigated; the teaching objectives and learning objectives can be decomposed, and then the contents of teaching and learning materials can be selected and supplemented. In addition, based on complex and dynamic data, from the perspective of big data, users can choose teaching resources according to their actual needs and adopt different media means for learning, so as to achieve better learning results.

\section{(3) Multi-dimensional}

Big data can make language appear in the form of an encyclopedia, which contains language products of various communication occasions such as environment, society and nature. Based on the teaching resources developed by English teaching and learning materials with big data, in addition to the text resources development, it will also be combined with the image, video, sound and other information, to provide multimodal language input for learners. By investigating the learners' multi-modular cognitive pattern, big data learning materials can help learners' language learning or acquisition, understand the characteristics of the regular pattern of language development, and improve the ability of language. 


\subsection{Implementation paths}

The development of big data-based College English learning materials will be divided into three steps. First, combine computer technology and big data analysis step by step. Second, integrate personalized design and language acquisition rules with a unique and novel way. Third, develop new College English textbooks that meet the needs of times and the requirements of students.

\section{(1) Construction of big data based English learning behavior indicator system platform}

Combined with the big data platform, the index system of college students' English learning behavior can be constructed. The interrelated and independent educational data are sorted out and integrated to predict students' English learning behavior, so as to understand and predict students' learning behavior at school comprehensively. The data sources of students' learning behaviors can be accessed through educational administration scores, English scores in College Entrance Examination, book borrowing records, competition awards and via student questionnaires. Through the questionnaire survey, the initiative of learning English and dynamic performance of related students can be understood. According to school's data management platform, English credits and academic point's average and classification of students can be revealed. Through the number of English books borrowed, and the frequency of going to library, and the times of language competition winning, learning results can be associated with it, which is helpful to construct learners' portrait. These data can accurately map the characteristics of college students' English learning behavior, contain the behavior rules of students, and provide English learning behavior prediction for different kinds of students by analyzing the data.

\section{(2) Development of big data-based English teaching and learning materials}

Big data-based English textbooks are divided into big data-based instructional materials and learning materials. Big data-based Instructional materials are small in scale and aim to enable students to narrow down the learning content and learn English in limited classroom time through organized listening, speaking, reading and writing practice, observation, discussion and reflection. Big data-based learning materials refer to a large amount of real and natural language corpus collected outside the teaching field, which is relatively large and can be used by teachers in designing tasks and make students in extension-based learning.

Through measurement, data collection, analysis and reporting learners and their environmental data, as well as learners' anticipation and application, the needs of teaching and learning materials can be investigated and the teaching goals and learning goals can be broken down based on learners' learning behavior analysis. By considering the macro factors, such as national policy, social requirements, local culture and so on, it is possible to research and develop big data-based English textbooks suitable for learners. Traditional paper English textbooks have a complete knowledge system and practical content. However, the content capacity of paper textbooks is relatively limited. Generally speaking, a unit can only cover three articles at most, which is far from enough to meet the reading capacity of the language. The e-teaching platform based on the big data teaching and learning materials has various forms and large storage capacity, creating teaching forms with the advantages of multimedia integration, man-machine interaction, diversity, portability, which can effectively improve the learning efficiency. The e-teaching system of big data-based teaching and learning materials appears in front of students in the role of learning companion and mentor, which overcomes the space-time limitation of teacher-student interaction. The system can track students' learning status through "push", "remind" and other ways, to judge, encourage and guide students' learning. Through human-computer interaction to guide students to study autonomously, the educational pursuit of "letting students be the master of learning" is truly realized. The electronic system platform of big data-based English teaching and learning materials can keep learners' learning records, and also provide the communication area or comment board for learners to reflect, interact and discuss, so as to enrich the user's experience, enhance his interest, interaction and competitiveness of learning.

\section{(3) Application of big data public English teaching and learning materials}

The use of College English textbooks based on big data in class is characterized by data-driven teaching with students as the main body, autonomous learning and practice. In class, task-driven teaching is adopted. Tasks are set in class to let students read the mini-texts prepared by the teacher in advance within the prescribed time, and then discuss, summarize and practice by themselves. In order to fully mobilize the enthusiasm of students, teachers should pay attention to the fact that each group participating in the discussion is composed of students at all different levels, which aims to expect students with better skills to help weaker students and ensures that every student can actively participate. Teachers are not only the executors of teaching and learning materials, but also the maintainers and revisers of teaching and learning materials. They adjust the teaching plans according to the constantly changing behaviors, learning interests, learning needs and learning strategies of learners, and make choice or supplement of the contents of textbooks on the open big data-based teaching platform. 
The big data-based learning materials can choose the corpus in the market, such as COCA and iWeb. COCA and iWeb corpora are composed of about 100 million corpora, covering five major categories, including spoken language, novels, popular magazines, newspapers and academic journals. Whether at COCA or iWeb, students can create a "virtual corpus" -- a personalized corpus. In just four or five seconds, students can build a "virtual corpus" that can be based on anything from chocolate to basketball, form solar energy to investing as well as Buddhism. Students can choose appropriate materials according to their own learning interests and learning needs to independently complete the established learning objectives. The era of big data has brought abundant teaching resources, providing real corpus, the most extensive topics, dynamic communication process, real language combination series, and integrated communication records of in-class and out-of-class learning (Zheng Tongtao, 2016). Therefore, the research and development of big data-based learning materials also needs to develop multi-level flexible and dynamic learning materials, such as audio, video, animation and so on, so as to maximize the language learning effect.

\section{Conclusion}

China is experiencing a strategic transformation from a large country to a powerful country in foreign languages education (Shen Qi, 2019). Textbooks are the means to realize the teaching goal. The final purpose of College English textbooks is to guide students to learn. Effective foreign language teaching can provide a suitable environment to help learners find the best individual learning path based on the overall language resources exploration, discovery, restructuring and innovation. (Zheng Yongyan, 2019). From the perspective of Complex Dynamic System Theory, the research, with the development and changes of times, has developed new big data-based English teaching and learning materials with digitalized, personalized and multidimensional characteristics, providing new ideas for China's College English teaching and learning materials development to better cultivate English talents in China.

Funding: This research was funded by Shanghai Foreign Language Education Press (2016SH0004B) and East China University of Science and Technology (No number exists.)

Acknowledgments: This paper would like to thank the following funding sources: National Foreign Language Teaching and Research Program for Colleges and Universities supported by Shanghai Foreign Language Education Press (2016SH0004B) and 2019-2020 Postgraduate Teaching Book Project Translation and International Communication supported by East China University of Science and Technology.

Conflicts of Interest: The authors declare no conflict of interest.

\section{References}

[1] [1] Cai J. G. (2011). A new breakthrough in editing principles of College English materials. Technology Enhanced Foreign Language Education, (05),3-9.

[2] [2] Chen J. L. (2007). The present situation and reform of College English teaching textbooks -- the conception of the research and development of the fifth-generation teaching textbooks. Foreign Language Teaching and Research, (05),374-378.

[3] [3] De Bot, K., \& Larsen-Freeman D. (2011). Researching second language development from dynamic systems theory perspective. In M. Verpoor. K de Bot \& W. Lowie (eds.) A dynamic approach to second language development. John Benjamins. 5-23

[4] [4] De Bot, K., Lowie W., \& Verspoor, M. (2007). A dynamic systems theory approach to second language acquisition. Bilingualism, 10 (1): 7.

[5] [5] Guo Y. \& Xu J. F. (2013). A Survey on the use and evaluations of College English teaching materials among non-English major college students. Foreign Language Research, (06),102-108.

[6] [6] Larsen-Freeman, D. (2017). Complexity theory: The lessons continue. In Ortega L. \& Han Z. (eds.) Complexity theory and language development: In celebration of diana Larsen-Freeman. John Benjamins. 11-50.

[7] [7] Lin S. C. \& Xiao L. Z. (2015). The second development of teaching textbooks under the perspective of intercultural communication A case study of the second edition of New ideas College English audio-visual and speaking course volume 3. Ability and Wisdom, (09), 111112.

[8] [8] Liu H. N. (2013). A literature review on College English teaching materials study in the past 20 years. Technology Enhanced Foreign Language Education, (02),66-71.

[9] [9] Luo D. (2013). Strategies Research on the Re-development of Cultural Materials in College English Textbooks_-Taking Reading and Writing of "New horizon College English" for Example. Journal of Guizhou Normal University (Social Sciences), (01),158-160.

[10] [10] Lu H. B. \& Tao W. H. (2018). On Chinese elements in College English textbooks. College English Teaching \& Research, (06), 100-104.

[11] [11] Luo M. (2020). An overview of theoretical research on complex dynamic systems in recent ten years. Sinogram Culture, (04),69-70.

[12] [12] Shen J. (2019). 70 years of foreign language education planning of China: paradigm changes and strategic shifts. Journal of Xinjiang Normal University (Edition of Philosophy and Social Sciences), (05),68-77.

[13] [13] Su W. (2016). Evaluation on textbook—Learning English through culture: viewing, listening and speaking. Journal of Hubei University of Education, (11), 108-110.

[14] [14] Wang C. M. (2014). Idea creation and language imitation: An effective route to L2 learning and teaching. Foreign Language World, (02), 42-48.

[15] [15] Wang C. Y. (2015). Review and expectation of the compilation of domestic medical English textbooks (2000-2013). China Higher Medical Education, (06),8-9.

[16] [16] Wei W. Z. (2020). Innovation and practice in the compilation of College English textbooks in the new era — A review of New horizon College English (third Edition) audio-visual speaking course. Education and Vocation, (09), 114 
[17] [17] Xu D. D. (2016). Research on the publication of College English textbooks with curriculum development as the core under the background of MOOC. View on Publishing, (02),81-82.

[18] [18] Xu J. F., Zhu Q., Tang X. C. \& Guo Y. (2016). Compiling principles and features of the Video course in the new target College English series. Foreign Language World, (02), 16-22.

[19] [19] Yan L., Zhao D. F. \& Liu Y. Q. (2019). Evaluation study based on multimodality theory about a study package- —Taking OUC's College English series as an example. Journal of Shandong Radio and TV University, (03), 17-20+27.

[20] [20] Yuan J. \& Wang L. M. (2015). The study of knowledge structure of College English textbooks for arts and sports majors——from the perspective of connectionism. Heilongjiang Researches on Higher Education, (03), 174-176.

[21] [21] Zhang D. L. \& Zhang S. J. (2010). An investigation into the compilation principles of multimodal foreign language textbooks. Foreign Language World, (05),26-33.

[22] [22] Zhang L. (2013). On Application of Summative and Formative Assessment in English Writing Education. Overseas English, (16),5-6.

[23] [23] Zhang X. M. (2019). Reflections on tertiary English teaching materials development in the New Era. Foreign Language World, (06),88-93.

[24] [24] Zheng Y. Y. (2019). The CDST perspective on effective foreign language teaching. Contemporary Foreign Languages Studies, (05), 12$16+49$.

[25] [25] Zheng T. T. \& Zeng X. Y. (2016). Study on development of Chinese country-specific teaching materials based on big data. Overseas Chinese Education, (03),291-302.

[26] [26] Zhou X. H. (2013). "Secondary development" of College English textbooks: A case study of New horizons College English reading and writing course. Journal of Educational Institute of Jilin Province, (12),77-79.

[27] [27] Zhu Q. (2020). The compilation concept and features of the series of textbooks for English for specific purpose: Comprehensive course of scientific English. Journal of Jiamusi Vocational Institute, (02),155-157. 